\title{
EL VIDRIO ROMANO EN LA PROVINCIA DE ALICANTE *
}

\author{
M. DOLORES SANCHEZ DE PRADO \\ Universidad de Alicante
}

\begin{abstract}
Este trabajo pretende fundamentalmente dar a conocer un material muy postergado por la investigación arqueológica: el vidrio, que se ha encontrado con relativa frecuencia en las ciudades y necrópolis de la provincia de Alicante. En el vidrio recogido se pueden distinguir dos grupos:

- En las dos primeras centurias de nuestra Era se trata de un vidrio lujoso, de muy buena calidad, liso o decorado con motivos sencillos cuyo carácter es marcadamente oriental.

- A partir del siglo III d. C., la calidad de las piezas es menor, aunque las decoraciones más complicadas. Las fábricas occidentales se imponen progresivamente.

The aim of this study is to spread a sort of material quite ignored by the archaeologycal research: that's the glass, often obtained in the roman villages and necropolis of Alicante. With regard to its characteristics, we have found two different types:

- A top-quality glass, decorated with primitive motives, brought from oriental countries while 1 st and 2 nd centuries a. $C$.

- A medium-to-low quality glass, decorated with very complicated motives, brought european factories since 3rd century a. C. Quality in raw material was descending as production was getting higher.
\end{abstract}

El objetivo de este trabajo ha sido realizar un estudio preliminar sobre el vidrio antiguo, ciñéndonos al marco que ofrece la provincia de Alicante. Esta labor se nos reveló interesante y necesaria, ya que existía una falta total de estudios sobre el tema. El vidrio ha permanecido inédito en nuestros museos, salvo muy raras excepciones. Hasta ahora la atención del arqueólogo se ha dirigido hacia otros materiales que le ofrecerían resultados más brillantes. Pero últimamente esta tendencia está cambiando y paulatinamente se manifiesta un creciente interés por estos materiales de «segundo orden» que, en realidad, son importantes auxiliares cronológicos. Así, el vidrio se encuentra con frecuencia en poblados y necrópolis, pudiéndose citar a la Isleta de Campello, el Tossal de Manises, Lucentum, el Monastil y las Agualejas, Illici o el Portus como ciudades o importantes villas, necrópolis como L'Horta Major, Mas Blanc o el Montañar en Jávea. Por otra parte, el vidrio fue un artículo de lujo que nos sirve como indicador de unas relaciones comerciales en las que nuestra costa participó activamente.

El primer paso que dimos al inicio del trabajo fue la recogida de material por los museos municipales y provincial; también pudimos acceder a algunas de las colecciones particulares que poseían material de este tipo. Luego éste sería dibujado y descrito, siguiendo una tipología geométrica de las formas, manteniendo siempre su encuadre en el yacimiento del que procedía.

* Este trabajo es un resumen de nuestra Memoria de Licenciatura que, bajo la dirección del doctor Lorenzo Abad Casal, fue presentada en la Facultad de Filosofía y Letras de la Universidad de Alicante, obteniendo la calificación de «sobresaliente por unanimidad». 
El paso siguiente fue la bibliografía, tarea que resultó bastante problemática, ya que en España el tema ha sido tratado escasamente, lo cual nos llevó a la recogida de publicaciones extranjeras que habrían de ser básicas para nuestro estudio.

El trabajo original se estructura en dos grandes grupos: el vidrio prerromano y romano. Pero, para esta publicación, hemos considerado que la primera parte debía ser suprimida, pues los fragmentos hallados fueron muy escasos y mayormente son elementos de adorno, grupo que presenta una problemática distinta, ya que a través de los siglos tanto sus técnicas decorativas como formativas han permanecido invariables, lo cual dificulta extraordinariamente su adscripción cronológica. Así pues, nos hemos ceñido exclusivamente al vidrio romano, dando a conocer las piezas más significativas halladas en la provincia de Alicante. Estas se han catalogado según su forma en los siguientes grupos: Ungüentarios, Botellas, Cubiletes o Vasos, Cuencos, Copas, Platos y Jarros. El estudio tipológico se ha hecho siguiendo fundamentalmente la obra de C. Isings (1957); asimismo cuando ha sido posible hemos indicado los paralelos hallados en' otras excavaciones de la Península.

\section{UNGÜENTARIOS}

El ungüentario o balsamario es un tipo de recipiente destinado principalmente a contener perfumes o ungüentos. Son las piezas más comunes y numerosas del mundo romano, distinguiéndose numerosas formas que hemos ido analizando según su cronología.

\section{I.1. Ungüentario globular (Isings 10)}

Este tipo de ungüentario aparece generalmente con el cuello roto, pues, dado que eran cerrados una vez llenos, era necesario rompérselo para poder utilizar su contenido. Los ejemplares más tempranos se datan en época de Tiberio a Claudio, no continuando, al parecer, en el siglo II d.C. El ejemplar (Fig. 1, 1) que hemos recogido ha sido fabricado en vidrio mosaico; se trata de una técnica tanto formativa como decorativa. Esta consistía en colocar barritas de vidrio de distintos colores uniéndolas por la parte interior del molde y cerrándolas con un segundo molde. El conjunto era calentado hasta su fundición y el recipiente resultante se pulía luego, a fin de eliminar las irregularidades superficiales. La escasez de este tipo de vidrio en nuestra provincia y su carácter de pieza lujosa, hace que nos planteemos la posibilidad de que este ungüentario haya sido importado desde Italia, donde estaban establecidos algunos talleres alejandrinos, que fueron maestros en esta técnica durante el siglo I d.C.

\subsection{Aríbalo (Isings 61)}

Se trata de un tipo cuya forma se deriva claramente del bronce y la cerámica. En nuestra provincia sólo hemos recogido tres fragmentos (Fig. 1, 2-4), procedentes del estrato romano de la ciudad del Tossal de Manises. La cronología general para estas piezas es desde fines del siglo I d.C. a principios de la centuria siguiente, momento en el que alcanzarán su máxima popularidad, siendo muy numerosos entre las ruinas de Pompeya (ISINGS, 1957, p. 78). El aríbalo continuará durante el siglo II, aunque introduce algunas variedades, como el borde triangular y el vidrio coloreado. En momentos posteriores, se impondrá el vidrio incoloro y, a veces, la pieza se decora con hilos en relieve. El siglo IV marcará la decadencia del tipo, que dejará de fabricarse tras la época de Constantino (HARDEN, 1936, p. 252). 

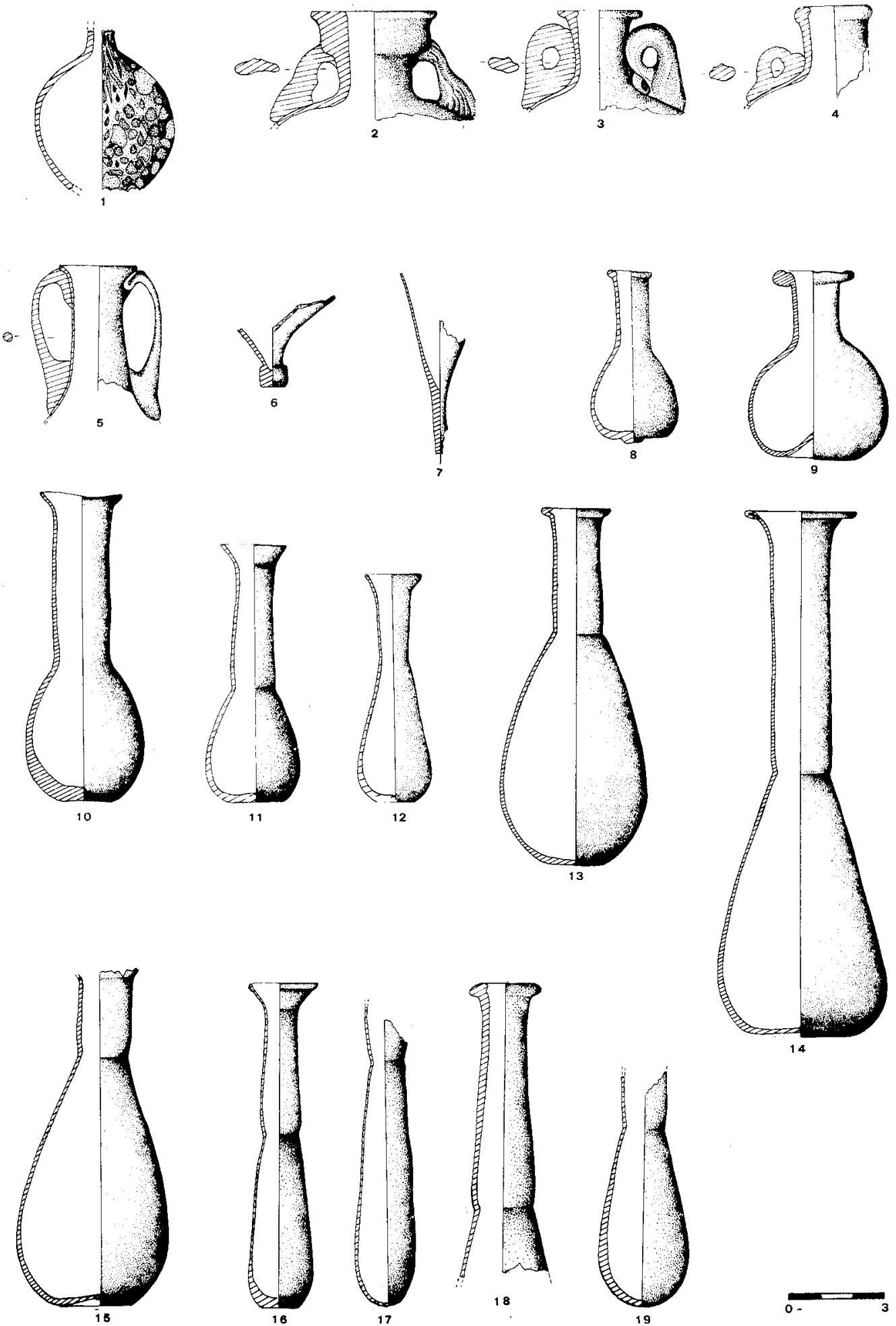

Figura 1.-Ungüentarios: 1, vidrio mosaico; 2-4, aríbalos; $3-7$, anforiscos; 8-15, piriformes; 16-17, tubulares. 


\section{I.3. Anforisco (Isings 15 y 60)}

Durante los dos primeros siglos de nuestra Era fue muy común el tipo de ánfora o botella con dos asas, que según su tamaño sería usada como ungüentario o botella. Calvi (1968, p. 21) distingue el ánfora de base plana, derivada claramente del metal, y el ánfora con cuerpo terminado en punta, que sería usada únicamente como ungüentario, dado su menor tamaño (Fig. 1, 5-7). Esta forma fue muy común tanto en la parte oriental como occidental del Imperio, datándose a partir de la segunda mitad de siglo I d.C., aunque se han hallado ejemplares más tardíos en Karanis (HARDEN, 1936, p. 258), que se fechan entre los siglos III-IV d.C., caracterizándose por su color verde-oliva, frente al verde-azulado de época imperial.

\section{I.4. Piriforme (Isings 6, 26 y 28)}

Se trata de una de las formas más comunes entre el vidrio romano, que sufrirá una continua evolución durante los dos primeros siglos de nuestra Era. El tipo más antiguo, de cuerpo piriforme y cuello cilíndrico, era hecho de vidrio coloreado, como nuestros ejemplares del Tossal (Fig. 1, 8) y Orihuela (Fig. 1, 9), que han de ser fechados hacia el 50 d.C. Paulatinamente el color verde-azulado se impondrá y la división entre el cuello y cuerpo, al principio muy marcada, se suaviza. Al mismo tiempo, el cuerpo del ungüentario se reduce hasta ocupar tan sólo $1 / 3$ ó 1/4 de su altura total (Fig. 1, 10-15).

Por otra parte, hay que añadir que dos pequeños ungüentarios (Fig. 1, 12), fueron hallados dentro de una urna cineraria de plomo, procedente de Elche, cuyo paralelo más próximo se encuentra en la Incineración Torres de Ampurias (ALMAGRO, 1955, Tabla Tipológica), datada en época de Tiberio-Claudio.

\section{I.5. Tubular (Isings 8 y 27)}

Este tipo se caracteriza por presentar un cuerpo cuyo ancho es casi igual al de su cuello. Fue muy numeroso durante el siglo I d.C., era hecho en vidrio verdoso o verdeazulado. El tipo más temprano se data en época julio-claudia, para hacerse muy popular en la segunda mitad del siglo. Su fecha final es más difícil de concretar, pues tanto entre el material de la Galia como en Karanis este ungüentario sigue apareciendo en contextos de los siglos III y IV d.C. (HARDEN, 1936, PL. XX, 834-835).

En nuestra provincia éste ha sido un hallazgo frecuente. Así en Alcoy (Fig. 1, 1617) y Elche (Fig. 2,1) se datan en el siglo I d.C. por su similitud con las piezas halladas en la Incineración Torres $n .^{\circ} 3$ y 5 de Ampurias (ALMAGRO, 1955) y con las halladas entre el ajuar de la sepultura XVI de la necrópolis del SE. de Baelo (REMESAL RODRIGUEZ, 1979, Fig. 20, 73/68), fechada en el período de Nerón y los Flavios. Entre las piezas de Tossal, hay que destacar una (Fig. 1,18), pues pertenece a un contexto más tardío, dada su fabricación en vidrio incoloro, que no se popularizaría hasta fines del siglo I d.C.; asimismo su borde es característico del siglo II. Finalmente, en Lucentum encontramos unos fragmentos en vidrio verde-amarillento, color típico del período tardorromano. Alguno conserva aún restos de un pequeño pie añadido, que nos llevó a compararlos a las piezas del Museo Real de Ontario (HAYES, 1975, n. ${ }^{\circ} 447-453$ ); éstas están decoradas con hilos en relieve y poseen dos asas, su cronología es de fines del siglo III y principios del IV d.C., al igual que un ejemplar de Barcelona (CARRERAS y VILLALBA, 1982, p. 20, n. ${ }^{\circ}$ 248). Así nuestras piezas (Fig. 2, 2-5), aunque fragmentadas, pueden adscribirse a esta cronología que encuadra con la general del yacimiento. 


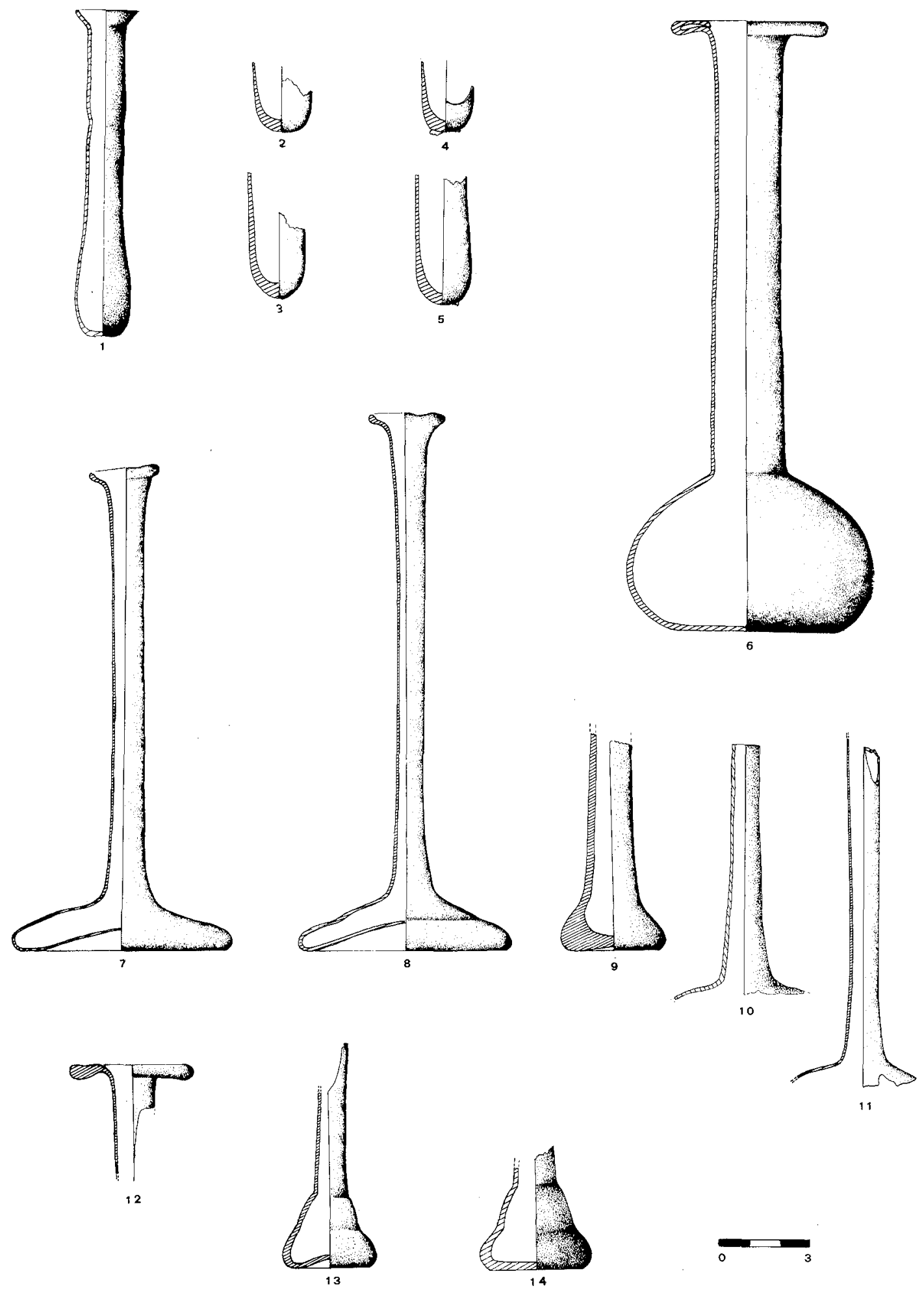

Figura 2.-Ungüentarios: 1-5, tubulares; 6-14, candelero. 


\subsection{Ungüentario de Candelero (Isings 82)}

Esta denominación agrupa varios tipos del característico frasco de largo cuello con cuerpo bajo y ancho. Según Vessberg $(1952$, p. 203) se trata de un recipiente con gran difusión por el Mediterráneo oriental y por el oeste, concretamente en el Valle del Ródano, donde debió fabricarse un subtipo, dado el gran número allí hallado con marca de fábrica.

La funcionalidad de estas piezas está clara por su parte más característica, el largo y estrecho cuello facilitaba el verter muy pequeñas dosis, al mismo tiempo que prevenía y evitaba la rápida evaporación del contenido.

Este ungüentario va a sufrir una continua evolución en sus formas. Según Calvi (1968, p. 134), los más antiguos son aquellos que presentan un cuerpo cónico y un estrangulamiento entre cuello y cuerpo (Fig. 2,6). Estos se fechan en la segunda mitad del siglo I d.C. en la región occidental, Renania y el Cantón Ticino, mientras que en Oriente, o sea Chipre, Egipto, Siria y Grecia aparecen en la segunda mitad de la centuria siguiente, continuando durante el siglo III d.C. Más tarde aparece un tipo más bulboso de perfil continuo y falto de división entre cuello y cuerpo (Fig. 2, 7-11), éste será muy popular entre los vidrios de Egipto, Chipre, Jerusalén y Colonia. En Chipre, aunque se originan en el siglo I d.C. se popularizan en el siglo siguiente; mientras que en Aquileia forman un grupo muy nutrido, llegando a pensar Calvi $(1968, p .139)$ que allí se hallaba un foco productor durante el siglo III d.C. El último tipo adopta una forma de campana (Fig. 2, 12-14; Fig. 3, 1-2). Este se encuentra entre el vidrio de la Galia y Chipre, donde se halló algún ejemplar en la tumba Limassol I, que se fecha en el 220 d.C.

Entre las piezas recogidas hay que destacar una (Fig. 3, 1), que fue hallada en una sepultura, junto al ungüentario se encontró una vasija decorada con los trabajos de Hércules, que recientemente se ha identificado como cerámica corintia, la cual era exportada a diversos lugares del Mediterráneo. Esta se fecha entre los siglos II-III d.C. (GRANADOS, 1977, p. 395).
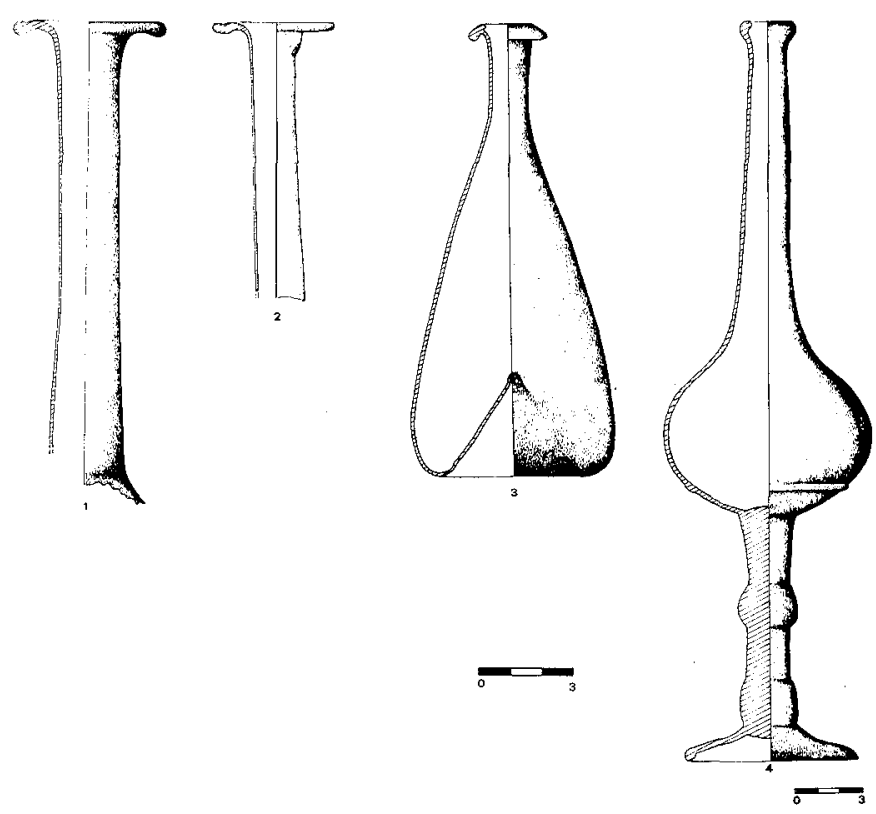

Figura 3.-Ungüentarios: 1-2, candelero; $3-4$, medievales. 


\section{I.7. Otros}

En nuestra provincia hemos recogido también algunas piezas que quedan adscritas al período intermedio entre la baja romanización y la época medieval. Así se destaca un ungüentario hallado en una sepultura del sector 6-F de la Alcudia (Elche). La necrópolis pertenece, según su excavador, a la ciudad del Bajo Imperio, datándola entre los siglos IV-V d.C. (RAMOS FERNANDEZ, 1974, p. 113). Sin embargo, una pieza procedente de Alcalá de los Gazules (CORZO SANCHEZ, 1981, p. 88, Fig. 6) es muy similar a la nuestra. Esta es fechada en torno al siglo VII d.C., dada la cerámica que salió acompañándola.

\section{BOTELLAS}

En el siglo I d.C. se originaron los tarros de cuerpo prismático con asas o sin ellas, de sección poligonal, generalmente cuadrada o rectangular. Algunos de ellos eran soplados al aire y otros dentro de un molde. Las botellas servían como envase para líquidos, ya que su forma las hacía muy estables y fácilmente transportables. Dentro de ellas hemos distinguido dos grupos:

1) Botellas con asas: siendo las más populares la cúbica y la cilíndrica.

2) Botellas sin asas: a este grupo lo denominamos frascos.

\section{II.1.1. Botella cúbica (Isings 50)}

Se trata de un recipiente muy común durante las dos primeras centurias de nuestra Era. El vidrio es generalmente grueso, de color verde-azulado y buena calidad. Charlesworth (1966, p. 28) distingue entre la botella soplada en molde o al aire, a la que luego se le aplanaban los lados y el fondo, dándole la forma cúbica. Las primeras suelen presentar su base decorada y su pared es bastante gruesa (Fig. 4, 6-7).

Cronológicamente, este tipo de botella no parece surgir antes del 70 d.C., popularizándose desde el período flavio en adelante, permaneciendo en uso durante los siglos II y III, pero ya en el siglo IV d.C. los hallazgos son muy escasos tanto en la parte occidental como oriental del Imperio (ISINGS, 1957, p. 65).

Entre las botellas recogidas, destacamos dos, que se conservan completas. Una (Fig. 4,1$)$ procede de la ciudad romana del Tossal de Manisses, la otra (Fig. 4. 5) de Illici. Esta última fue hallada en la boca número dos del alcantarillado romano de la ciudad. Junto a ella apareció cerámica sigillata clara, tipo 10 de Lamboglia, fechándose entre los siglos II y III d.C. Así este hallazgo nos marca la fecha tope para nuestro ejemplar, que encuentra un paralelo muy próximo en una botella hallada en la sepultura 22 de la necrópolis de Pollentia (Mallorca), y que se data entre los siglos I y II d.C. (ALMAGRO, 1953-4, p. 263).

\section{II.1.2. Botella cilíndrica (Isings 51)}

$\mathrm{Al}$ igual que el tipo anterior también es muy común durante las dos primeras centurias de nuestra Era en todo el territorio romano. El problema está al tratar el momento de su desaparición, ya que en Karanis (HARDEN, 1936, p. 234) aparece en contextos más tardíos, como los siglos II y III d.C., e incluso en hogares de niveles más altos. Nosotros tan sólo hemos recogido un fragmento de este tipo de botella (Fig. 5, 1). 

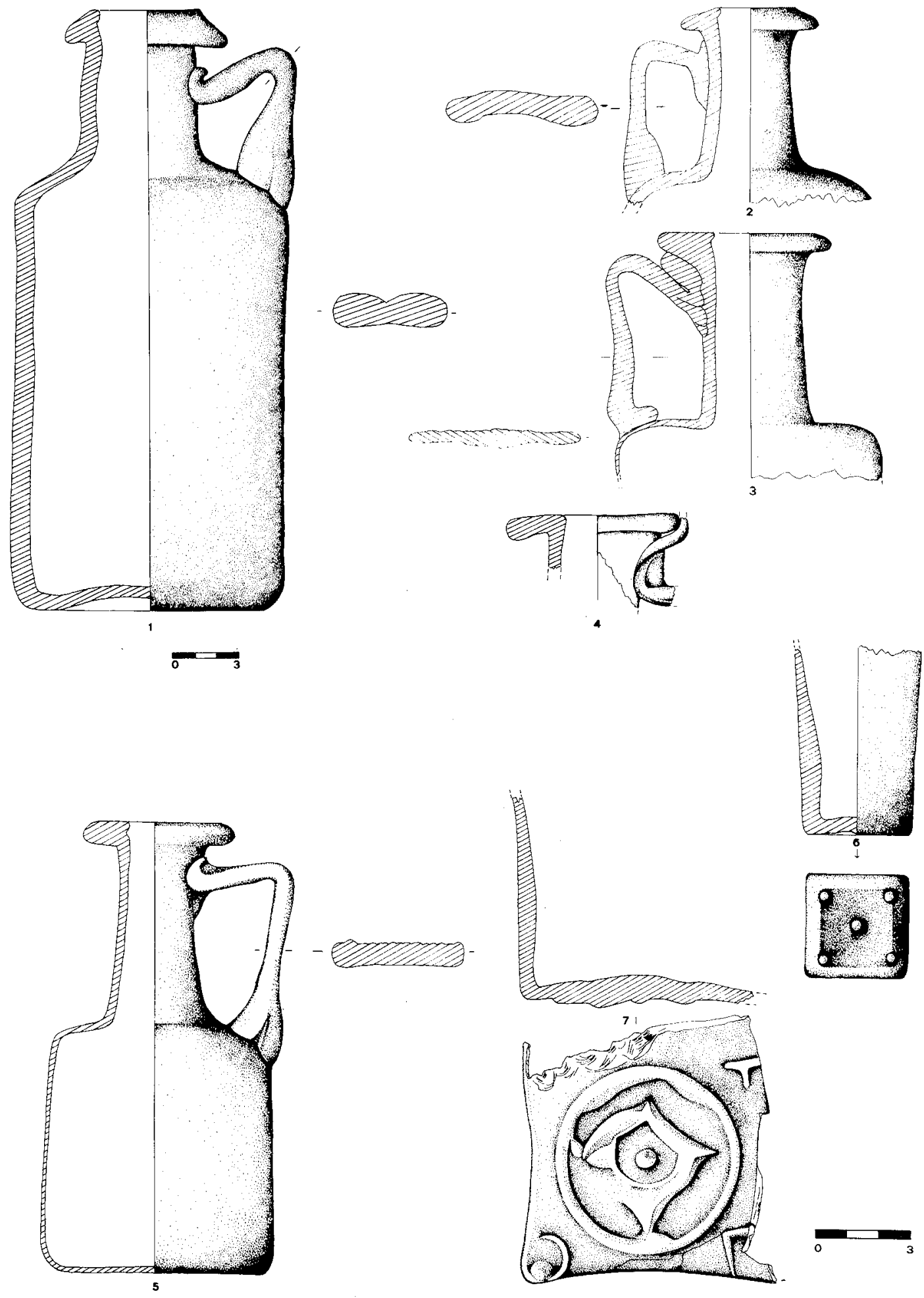

Figura 4.-Botellas: 1-7, botella cúbica. 

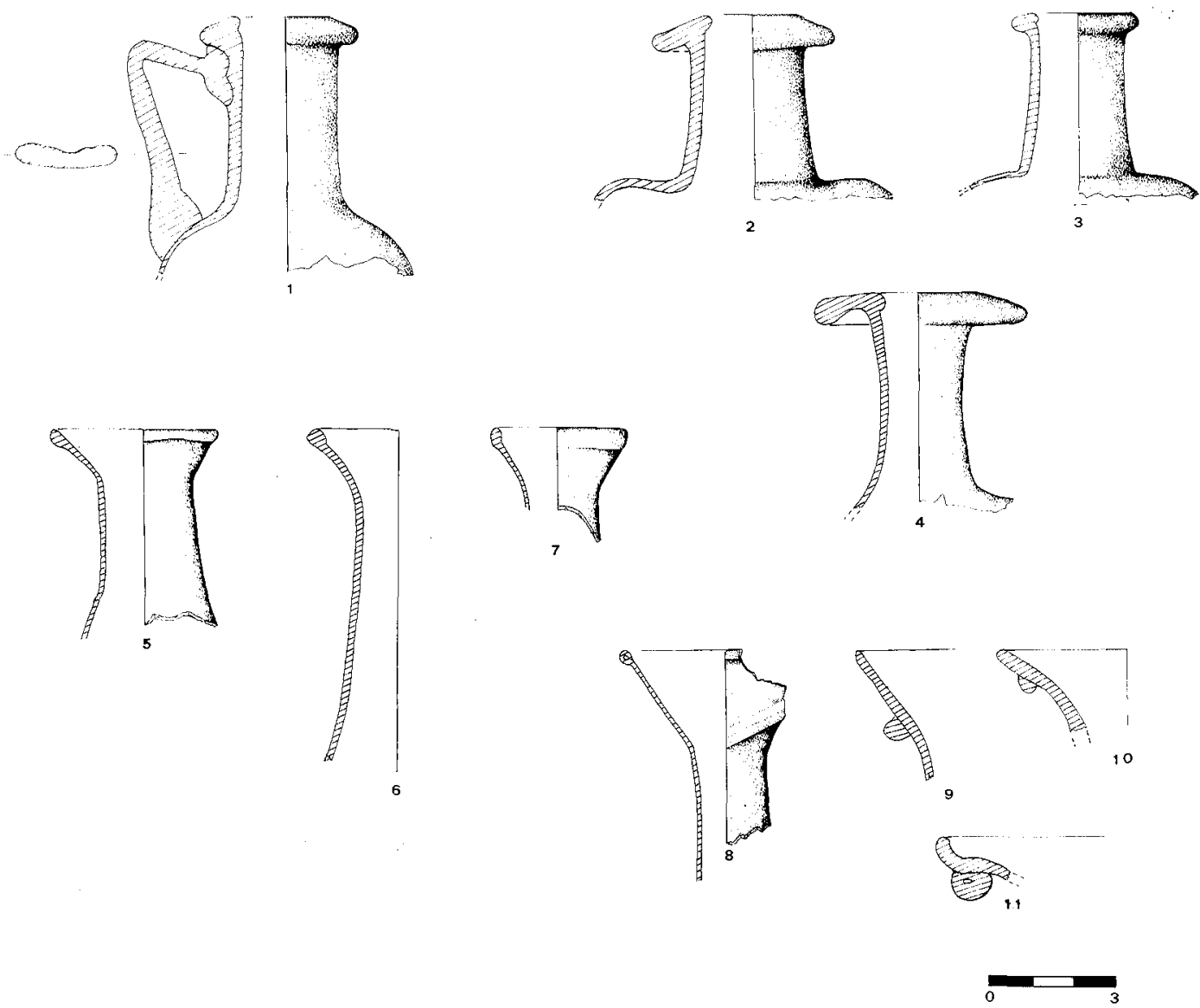

Figura 5.-Botellas: 1, botella cilíndrica. Frascos: 2-4, frasco con borde triangular; 5-11, frasco con boca de embudo.

\section{II.2. Frascos (Isings 102)}

Se trata de una forma muy corriente a partir del siglo III d.C. Los frascos podían ser esferoides, ovoides y sobre todo cilíndricos. Estos últimos se caracterizan principalmente por presentar una boca de embudo, muy frecuente en este siglo, sobre todo en la Galia, Egipto y Palestina. Los ejemplares recogidos se clasifican en dos grupos:

a) Frascos con borde triangular (Fig. 5, 2-4), que se pueden datar desde finales del siglo II al III d.C. Aunque en la Basílica paleocristiana de Alconétar (Cáceres), fue hallado un frasco de este tipo, por lo que parece continuar tras el siglo IV d.C. (CABALLERO, 1970, p. 43, Fig. 13, 54).

b) Frascos con boca de embudo (Fig. 5, 5-11), es una variedad muy numerosa, a veces está decorada con un grueso hilo de vidrio bajo el borde. El tipo parece proceder de Oriente, por el gran número de piezas halladas en Chipre, Egipto y Palestina, siendo muy escasas las procedentes de Occidente. En cuanto a su datación, Calvi (1968, p. 145) sostiene que su producción se iniciaría hacia mediados del siglo II d.C., siguiendo en la centuria posterior. Todas nuestras piezas proceden de yacimientos con clara cronología tardía, como son Lucentum, el Portus illicitanus y las Agualejas (Elda), cuyos materiales más significativos se datan en el siglo IV d.C. 


\section{VASO O CUBILETE}

Este recipiente suele presentar una altura que es el doble del ancho. El vaso será muy frecuente a partir de la segundá mitad del siglo I d.C., y tanto sus formas como decoraciones son muy variadas.

\section{III.1 Vaso soplado en molde (Isings 31)}

Este tipo de vaso debió ser de los más costosos, dado que se fabricaba con la técnica del soplado en molde, obteniendo un tipo de decoración que imita claramente a los vasos metálicos repujados. Tanto Calvi $(1968$, p. 101) como Hayes $(1975$, p. 48) apuntan un origen sirio para estos recipientes, aunque también pudieron fabricarse en el norte de Italia, hacia donde hubo una fuerte emigración de artesanos sirios a mediados del siglo I d.C., desde allí las exportaciones llegarían a todos los puntos del Imperio. El motivo decorativo que presentan es muy variado, pudiendo ser vegetal, animal o combinado. Cronológicamente se datan entre la segunda mitad del siglo I y principios del II d.C., no encontrándose con posterioridad. Nosotros hemos recogido dos fragmentos (Fig. 6, 1-2), éstos están decorados a base de hojas y brotes distribuidos a intervalos regulares, al igual que un ejemplar procedente de Pompeya (ISINGS, 1957, p. 45).

\section{III.2. Vaso con depresiones longitudinales (Isings 32)}

Este vaso se caracteriza precisamente por su decoración, que se obtenía al modelar la pared del mismo con un utensilio, cuando el vidrio estaba aún caliente. En general esta forma se difundió grandemente durante el siglo I d.C. por todo el Imperio, hallándose en toda el área del Mediterráneo: Pompeya, Thera, Corinto y Chipre. Ya en el siglo siguiente se extenderá por la región noroccidental, donde prevalecerá hasta el siglo IV d.C. (Forma 114 de Isings). En Karanis hallamos ejemplares procedentes de casas que se fechan hasta el siglo V d.C. En Alicante contamos con dos vasos fragmentados de este tipo (Fig. 6, 3-4), ambos proceden de la ciudad romana del Tossal de Manises, fechándose entre los siglos I y II d.C.

\section{III.3 Vaso con decoración aplicada (Isings 33)}

$\mathrm{Al}$ igual que el tipo anterior, este vaso presenta un motivo característico: anillos ovales o líneas onduladas en relieve. Se trata de un recipiente no demasiado común, aunque en Italia, Vindonissa y el Cantón Ticino se encuentran en gran número. Esa localización concreta y su contemporaneidad llevan a Calvi $(1968$, p. 58) a centrar su fabricación en la Italia septentrional. Cronológicamente, el tipo se origina en época de Claudio o Claudio-Nerón y continúa en auge durante las primeras décadas del siglo II d.C., para decaer casi totalmente a partir de la segunda mitad. En Alicante hemos recogido dos ejemplares, uno de la ciudad romana del Tossal de Manises (Fig. 6, 5) y el otro de Elche (Fig. 6, 6).

\section{III.4. EI vaso troncocónico (Isings 29-106)}

Este vaso es una de las formas aparecidas en el siglo I d.C., continuando en siglos posteriores, para imponerse a partir del siglo III d.C. El vaso troncocónico es muy frecuente entre el vidrio de la Galia, mientras que falta casi por completo entre el oriental. Este se adscribe a una cronología tardía, siglos III y IV d.C. Es interesante destacar el hallazgo de un vaso, de este tipo, liso, en la necrópolis de L'Horta Major (Fig. 6, 7), 

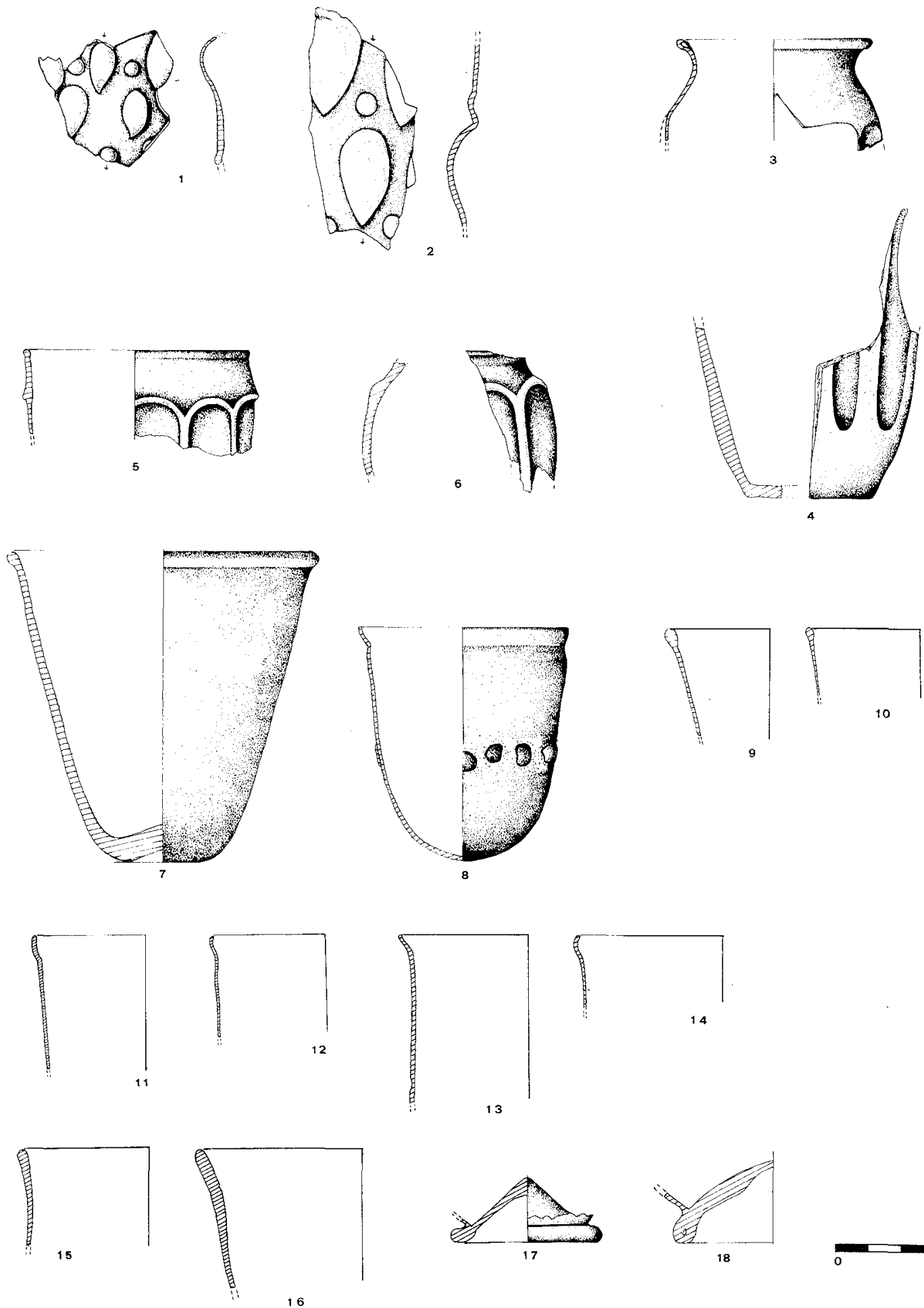

Figura 6.-Vasos o cubiletes: $1-2$, vaso soplado a molde; $3-4$, vaso con depresiones; $5-6$, vaso con arcos ovales; 7-10, vaso troncocónico; 11-14, vaso cilíndrico; $15-18$, vaso cónico con pie. 
junto a él apareció cerámica sigillata hispánica, formas Dragendorff 27 y 37 , de amplia cronología. El paralelo más próximo lo encontramos en la necrópolis de Fuentespreadas (CABALLERO, 1974, fig. 43, 1).

Otro vaso muy peculiar presenta una decoración de cabujones, que son gruesas gotas de vidrio, de color más oscuro, que eran vertidas sobre la pared del vaso (Fig. 6, 8). Se trata de un motivo muy característico del siglo IV d.C. Su paralelo más próximo es un vaso depositado en el Museo de Barcelona (CARRERAS, 1982, p. 7, n. ${ }^{\circ} 187$ ).

\section{III.5 EI vaso cilíndrico}

Es muy típico durante las dos primeras centurias de nuestra Era. Pero paulatinamente irá perdiendo terreno frente al vaso troncocónico, que se impondrá en el siglo IV d.C. En la provincia se han recogido algunos fragmentos de vasos cilíndricos (Fig. 6, 1114). Todos ellos presentan decoración, así acanaladuras o incisiones, que eran los motivos más populares en estos siglos, frente a otras más complicadas que se impondrán posteriormente, como los cabujones, los hilos fundidos o en relieve y el tallado.

\section{III.6 El vaso cónico con pie (Isings 109)}

Este vaso se caracteriza por presentar un pie anular, que ha sido obtenido al plegar la pared del mismo. Así su parte inferior se estrecha, dando la apariencia de un vástago. Se trata de un tipo muy común a partir del siglo IV d.C. e incluso llega a perdurar hasta el siglo VI. El tipo parece ser occidental, siendo muy abundante en la Galia. Nuestros ejemplares, muy fragmentados, proceden todos ellos de yacimientos tardorromanos, como Lucentum, Elche, el Monastil y las Agualejas (Fig. 6, 15-18). En la Península tan sólo hemos hallado un vaso de este tipo en Castiltierra (Segovia), que se conserva en el Museo del Instituto de Valencia de Don Juan (VIGIL, 1969, p. 170).

\section{CUENCOS}

El cuenco es un recipiente cuyo diámetro de boca es igual o algo inferior a su altura; su relativa profundidad es lo que establece la diferencia con los platos, que muchos autores denominan «Cuencos poco profundos» («Shallow Bowl»).

\section{IV.1 Cuencos de costillas (Isings 3)}

Estos constituyen un tipo muy característico del siglo I d.C. y deben su denominación a su peculiar decoración de suaves costillas en relieve que desde el borde descienden hasta el fondo de la vasija. En un primer momento, estos cuencos se fabricaban en vidrio mosaico, pero poco a poco se fue imponiendo el vidrio monocromo. Técnicamente, encontramos ejemplares moldeados, soplados e incluso soplados en molde.

Los cuencos moldeados imitan modelos metálicos que se remontan a época de los Ptolomeos. El vidrio viscoso se prensaba en un molde con los relieves en negativo, o bien se rellenaba éste de vidrio triturado que luego se calentaba al horno para su fundición. Los moldes podían ser sencillos o dobles. Esta técnica se usaba ya en el tercer milenio a.C., alcanzando su máxima difusión a mediados del primer milenio. En cuanto al soplado, el proceso era el siguiente: con un tubo de metal se recogía por un extremo un poco de vidrio del crisol y por el otro se soplaba hasta formar una bola de vidrio, a la que se le iba dando forma y moldeando dentro del horno. El cuenco soplado va generalmente decorado con hilos blancos fundidos. Otra técnica es el soplado en molde, con la que se obtenía directamente la decoración (Fig. 7, 2). Esta fue una producción de la ofi- 

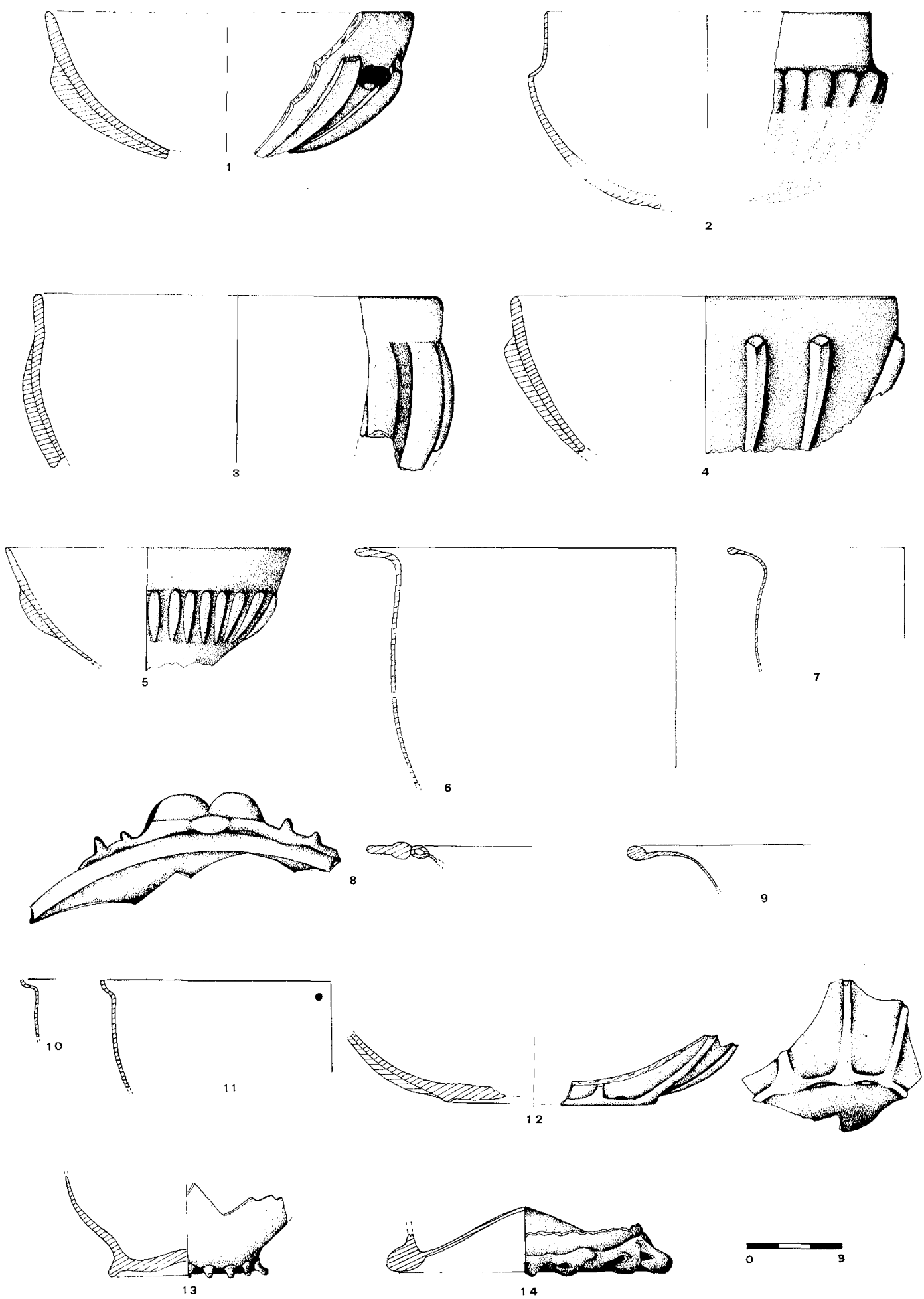

Figura 7.-Cuencos: 1-5, cuencos de costillas; 6-9, cuenco con pie anular; 10-11, cuenco elipsoide liso; 12-14, cuenco elipsoide pinzado. 
cina romano-siria, resultado de la fuerte emigración de artesanos sirios a otras regiones del Mediterráneo oriental e Italia a mediados del siglo I d.C. (CALVI, 1968, p. 101).

El cuenco de costillas se fabricará durante todo el siglo I d.C. Isings (1957, p. 17) divide al grupo en tres tipos, aquellos con nervios alargados hasta la base son frecuentes en época de Claudio-Nerón, continuando hasta los Flavios (Fig. 7, 1-4). Pero el cuenco con nervios sólo en el centro del cuerpo (Fig. 7,5) se origina en época de Claudio, ya que no existe ninguno en tiempos de Augusto. Por otra parte la pieza fabricada en molde (Fig. 7,2$)$ responde a un tipo muy frecuente en las provincias orientales, que se fabricaba según dos variantes: una más baja con molduras inferiores y otra más alta sin molduras. Nuestro ejemplar es muy similar a otro hallado en Conímbriga (ALARÇAO, 1976, PL XXXV, 43).

\section{IV.2. Cuenco con pie anular (Isings 42-43)}

Son varios los tipos que presentan este pie. Así el primero es de paredes convexas y borde horizontal con labio redondeado (Fig. 7, 6-7). Fue hallado en gran número entre el material de Herculano y Pompeya. Según Isings (1957, p. 21) este recipiente de vidrio es una copia de las formas metálicas y cerámicas, como la 35 de Dragendorff. Cronológicamente, se sitúan a partir de época flavia, siguiendo durante el siglo II d.C. e incluso se adentra algo en la centuria siguiente. En España conocemos el hallazgo de otro cuenco similar en la necrópolis del Pradillo (Badajoz), cuando se excavaba la tumba $n .^{\circ} 5$; junto a él apareció una botella hexagonal. El conjunto sería fechado entre Claudio y Vespasiano, dada la presencia de una lucerna del tipo II B3 de Ponsich (DEL AMO, 1973, p. 75).

El otro subtipo se caracteriza por las asas, las cuales se forman con gruesos hilos del mismo vidrio y se añaden al borde. Nosotros hemos recogido un ejemplar procedente del Tossal de Manises (Fig. 7,8). Se trata de una pieza hecha en vidrio incoloro, por lo que la podemos datar a finales del siglo I d.C., momento en el que se generaliza este tipo de vidrio.

\section{IV.3. Cuenco elipsoide (Isings 96)}

Este se encuentra tanto liso como decorado. La variedad sin decoración forma en Chipre un grupo muy homogéneo, esto lleva a Calvi (1968, p. 67, «Coppe» CY) a apuntar una misma procedencia para todos ellos, quizás de una fábrica chipriota. Este cuenco imita a los tipos metálicos del siglo I d.C., aunque en vidrio empieza a fabricarse como pronto en el siglo II d.C. Nosotros sólo hemos recogido dos fragmentos (Fig. 7, 1011). Ambos proceden del Monastil (Elda), yacimiento tardorromano, que alcanza su máximo esplendor en el siglo III, perviviendo hasta los siglos V y VI d.C.

En cuanto al cuenco decorado, encontramos variados motivos. Así el pinzado, decoración obtenida cuando el vidrio está aún caliente. Se trata de un tipo poco común en las regiones orientales e italianas, en cambio entre el vidrio galo es muy frecuente durante los siglos III y IV d.C. (CALVI, 1968, p. 51). En Alicante hemos recogido tres fragmentos de cuencos pinzados, dos de ellos (Fig. 7, 12-13) proceden del Tossal de Manises, mientras que el otro, de factura más tosca (Fig. 7, 14), procede del Portus illicitanus.

Otra decoración típica de estos siglos es el cabujón, que hemos visto en alguna pieza anterior. Estas gotas de vidrio quedaban aplastadas como un disco y solían ser de color más oscuro que el recipiente, así: verde, azul, violeta, o rojo, mientras que el vidrio del recipiente solía ser incoloro. Esta decoración es típica del siglo IV d.C., aunque en el Este perdurará durante el período árabe. En Renania estos cuencos fueron muy nume- 
rosos, extendiéndose por un área que parece tener como centro a Colonia; posteriormente aparecen por la zona danubiana e Italia, donde los cabujones son monocromos, frente a la policromía alemana. Nuestro único ejemplar (Fig. 8,1) procede de Elche y es muy similar a otro hallado en la necrópolis de San Miguel del Arroyo, que se fecha entre el 351-354 d.C. (CABALLERO, 1974, p. 146).

\section{IV.4. Cuencos poco profundos (Isings 11)}

Bajo esta denominación recogemos un tipo de cuenco característico de los siglos IV y V d.C. Estos se nos presentan tanto lisos como decorados, destacando las líneas talladas o hilos blancos fundidos, aunque la distinta decoración no conlleva una cronología diferenciada.

El tipo liso ha sido hallado en gran número en la ciudad romana de Lucentum (Fig. 8, 2-21). El vidrio es incoloro o verde oliva, recubierto por una pátina negra. En Alconétar (CABALLERO, 1970, p. 54) se hallaron también varios fragmentos al hacer una cata al sur de la Basílica. Junto al vidrio apareció cerámica sigillata hispánica tardía, el nivel fue datado entre los siglos IV y V d.C.

Otros nos han aparecido decorados con líneas incisas (Fig. 8, 22-29), la mayoría proceden igualmente de Lucentum. Igual ocurre con los decorados con hilos blancos fundidos (Fig. 8, 30-34; Fig. 9, 1-7). Esta decoración es original de Siria y debió empezar a usarse a fines del siglo II d.C., aunque en Occidente se generalizaría a fines del siglo IV e incluso durante el siglo VI d.C., principalmente en Renania, Bélgica y NE. de Francia. Los hilos normalmente blancos se aplicaban en caliente, fundiéndose en la superficie del recipiente. Este tipo es frecuente en Lucentum, en Elda también se ha encontrado algo de este tipo, así se conserva un fondo decorado con una roseta (Fig. 9, 7) que encuentra su paralelo más próximo en otro de Conímbriga (ALARÇAO, 1976, PL/XLIII, 223) y en otro de Villaricos (SIRET, 1906, LXXVIII, 32).

Finalmente, hemos recogido otros con decoración soplada (Fig. 9, 9-10) ambos proceden de Lucentum. Resulta significativa esa frecuencia de aparición en el yacimiento de Lucentum, pudiéndose pensar que aquí existió una fábrica de vidrio que produciría, entre otros tipos, estos cuencos.

\section{COPAS}

En este grupo incluimos aquellos recipientes que presentan un vástago o peana sobre la que se sustentan.

\section{V.1 Cántharos (Isings 38)}

El Cántharos clásico con altas y curvadas asas, no parece sobrevivir al siglo I d.C. Muchos eran hechos de vidrio coloreado y no sólo del vidrio corriente verde-azulado. En España se han encontrado algunos ejemplares en Palencia, Cádiz y Sevilla (VIGIL, 1969, p. 131). Entre nuestro material tenemos una pieza procedente de Elche (Fig. 10, 2), aunque fragmentada, y otra del Tossal (Fig. 10, 1), a la que le falta tan sólo el borde.

\section{V.2 Copas de pie alto (Isings 111)}

En el siglo IV d.C. hay un tipo provisto con un alto pie con vástago, el cual podía quedar parcialmente hueco o totalmente sólido. Estas copas suelen encontrarse con relativa frecuencia entre el material de Karanis, donde Harden (1936, p. 167) las data a partir del siglo IV. Muchas de ellas aparecen decoradas con hilos serpentiformes, sobre 

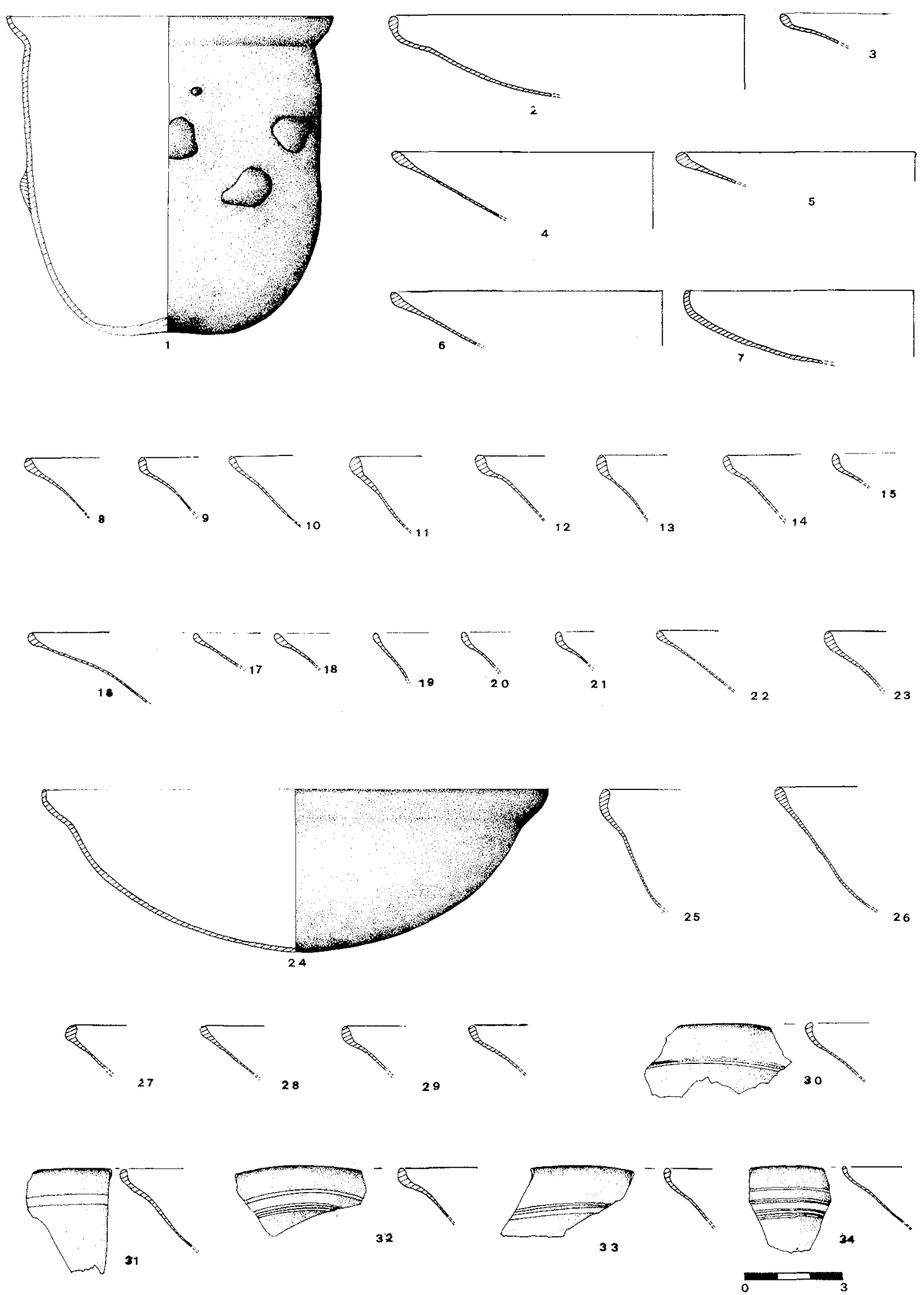

Figura 8.-Cuencos: 1, cuenco elipsoide con cabujones; 2-21, cuencos bajos lisos; 22-29, cuenco bajo con incisiones; 30-34, cuenco bajo con hilos fundidos. 

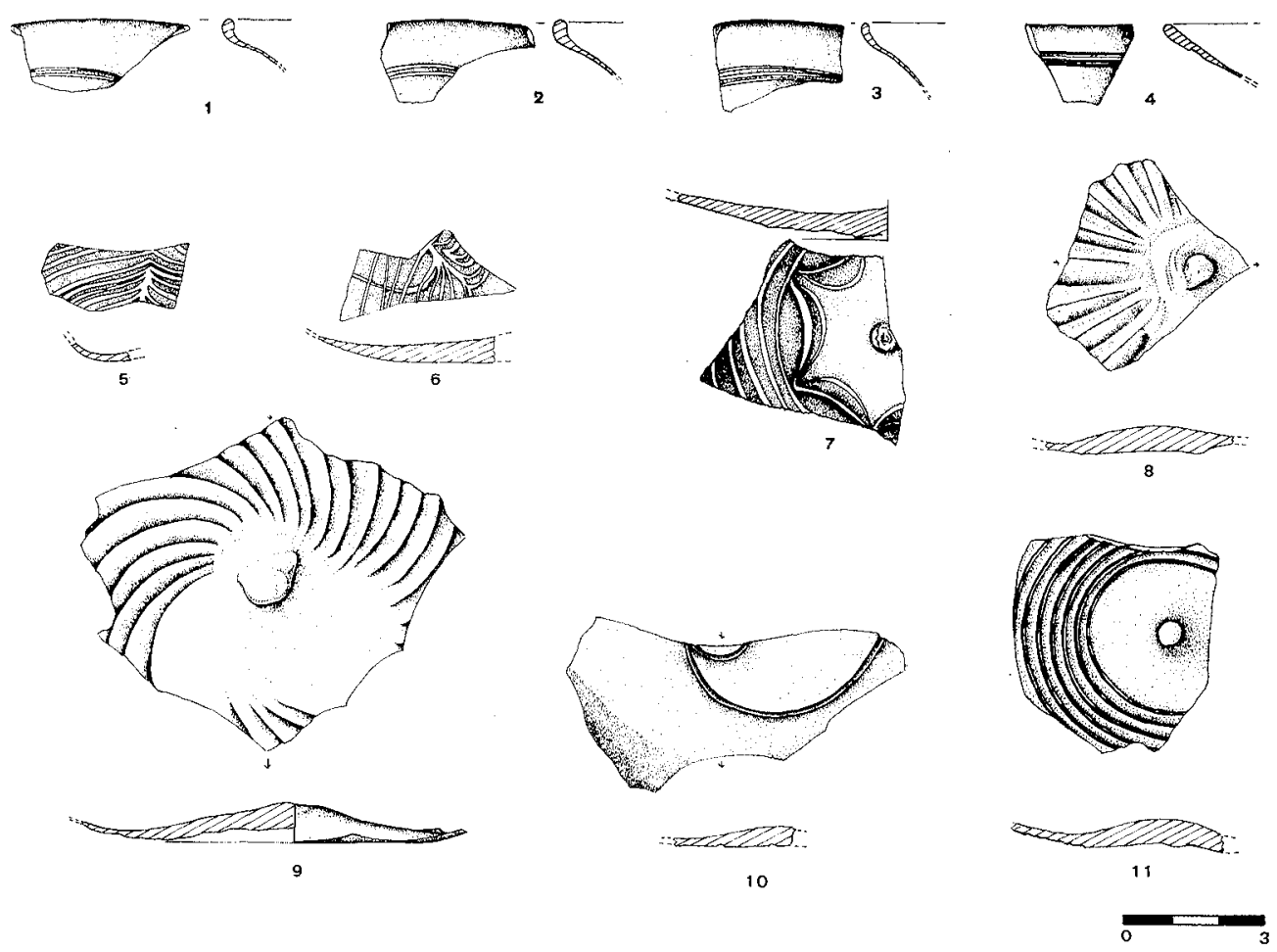

Figura 9.-Cuencos: 1-7, cuenco bajo con hilos fundidos; 8-11, cuenco bajo con decoraciones diversas.
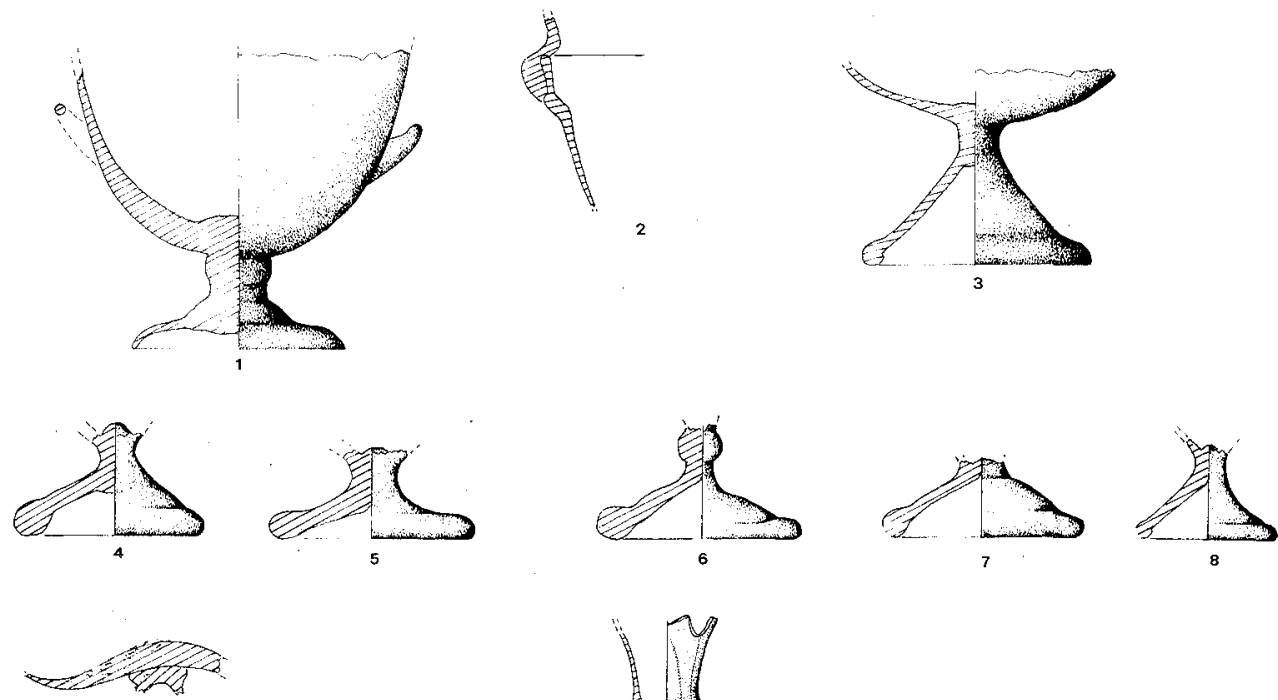

9
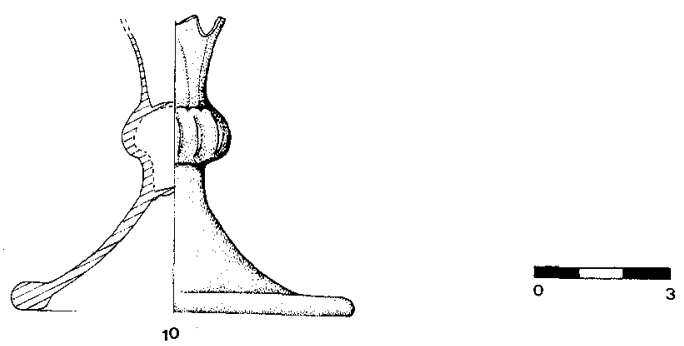

Figura 10.-Copas: 1-2, cántaros; 3-10, copas de pie alto. 
todo en Occidente. Así Harden llega a sostener la existencia de dos focos de producción, uno en Colonia y el otro en Alejandría, aunque en un principio el tipo fuera oriental (ISINGS, 1957, p. 139; VESSBERG, 1952, p. 199). Estas copas perviven largo tiempo, habiéndose encontrado ejemplares en Gerasa (s. VI-VII d.C), en el Mitreo de Santa Prisca, Roma (s. IV d.C) y en cementerios francos del siglo VII d.C.

En Lucentum hemos recogido varios vástagos que se relacionan con esta forma (Fig. 10, 4-9). Estos son muy similares a otros del Museo Real de Ontario (HAYES, 1975, Fig. 11, 381 y 653), que se datan entre los siglos V y VI d.C.

\section{PLATOS}

En las dos primeras centurias de nuestra Era se impone el plato circular, hecho generalmente de vidrio verde-azulado. Este tipo solía presentar pie y paredes verticales. Fue muy común en Italia, por el contrario falta casi por completo del vidrio egipcio y sirio. Pero a partir del siglo III d.C. se impondrá el plato oval de pie anular y borde plegado. Estos son muy numerosos entre el vidrio de Karanis y alcanzan su máxima difusión al inicio de la centuria siguiente.

\section{VI.1 Platos moldeados (Isings 2)}

Los platos hondos y moldurados, de vidrio incoloro, son relativamente frecuentes en Conímbriga (ALARÇAO, 1976, p. 171). Al parecer eran hechos dentro de moldes a presión y luego pulidos a torno. Hasta el 50-60 d.C. éstos se hacían de vidrio coloreado, para más tarde imponerse el vidrio incoloro. En nuestra provincia sólo hemos recogido cuatro platos moldeados, dos de ellos (Fig. 11, 2-3) proceden de la colección de los PP. Jesuitas, y están hechos de vidrio incoloro. La otra pieza mayor es de Lucentum (Fig. $11,4)$, se trata igualmente de un plato circular e incoloro. Entre el material de Pompaelo (MEZQUIRIZ, 1978, Fig. 43, 1-2) encontramos varios ejemplares iguales a nuestro plato, éstos se datan entre los siglos I-III d.C., ya que pertenecen a los estratos VI y V, donde aparecieron monedas de Cómodo y Alejandro Severo. Finalmente tenemos un plato moldeado con decoración, que procede del Tossal de Manises (Fig. 11, 1). Este es semejante a la forma 22 de Isings $(1957$, p. 38), que se data en época de Tiberio y Claudio, desapareciendo a mediados del siglo I d.C.

\section{VI.2 La pátera paleocristiana (Isings 118)}

Esta pátera, procedente del Portus illicitanus, se encuentra hoy depositada en el Museo Arqueológico Nacional. Posee un alto pie y está decorada con motivos grabados, técnica muy empleada a partir del siglo III d.C., tanto en Oriente como en Occidente. Su motivo central es un Crismón, el cual se ensancha mucho por sus extremos, lo que nos lleva a datar la pieza en el siglo IV d.C.

\section{JARROS}

El jarro fue un recipiente muy común en todo el Imperio. Según Harden (1936, p. 231) los tipos más elaborados fueron probablemente usados como jarros de mesa, para el vino o aceite; y otros más sencillos, serían usados para transportar líquidos. 

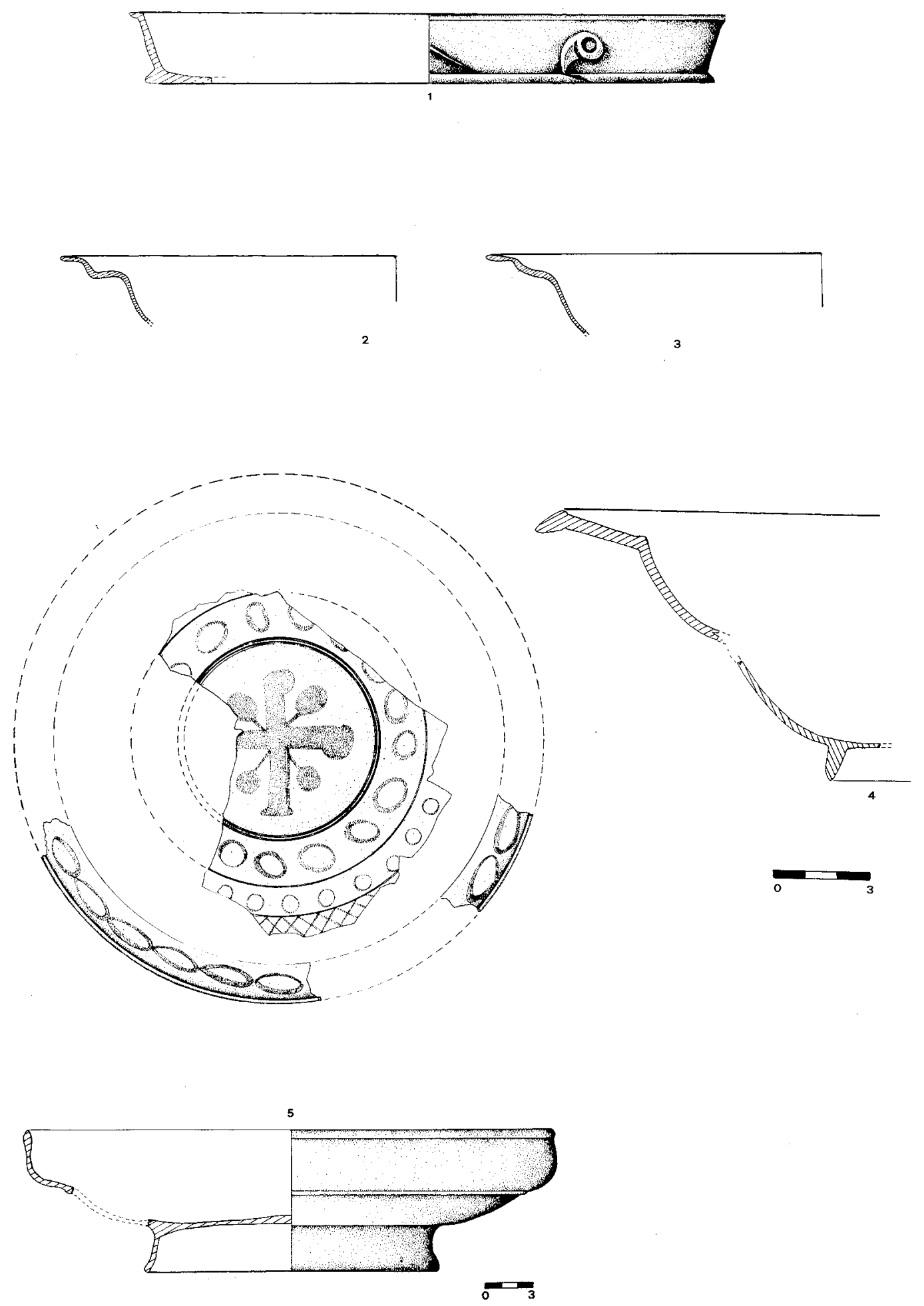

Figura 11._-Platos: 1-4, plato moldeado; 5, pátera paleocristiana. 

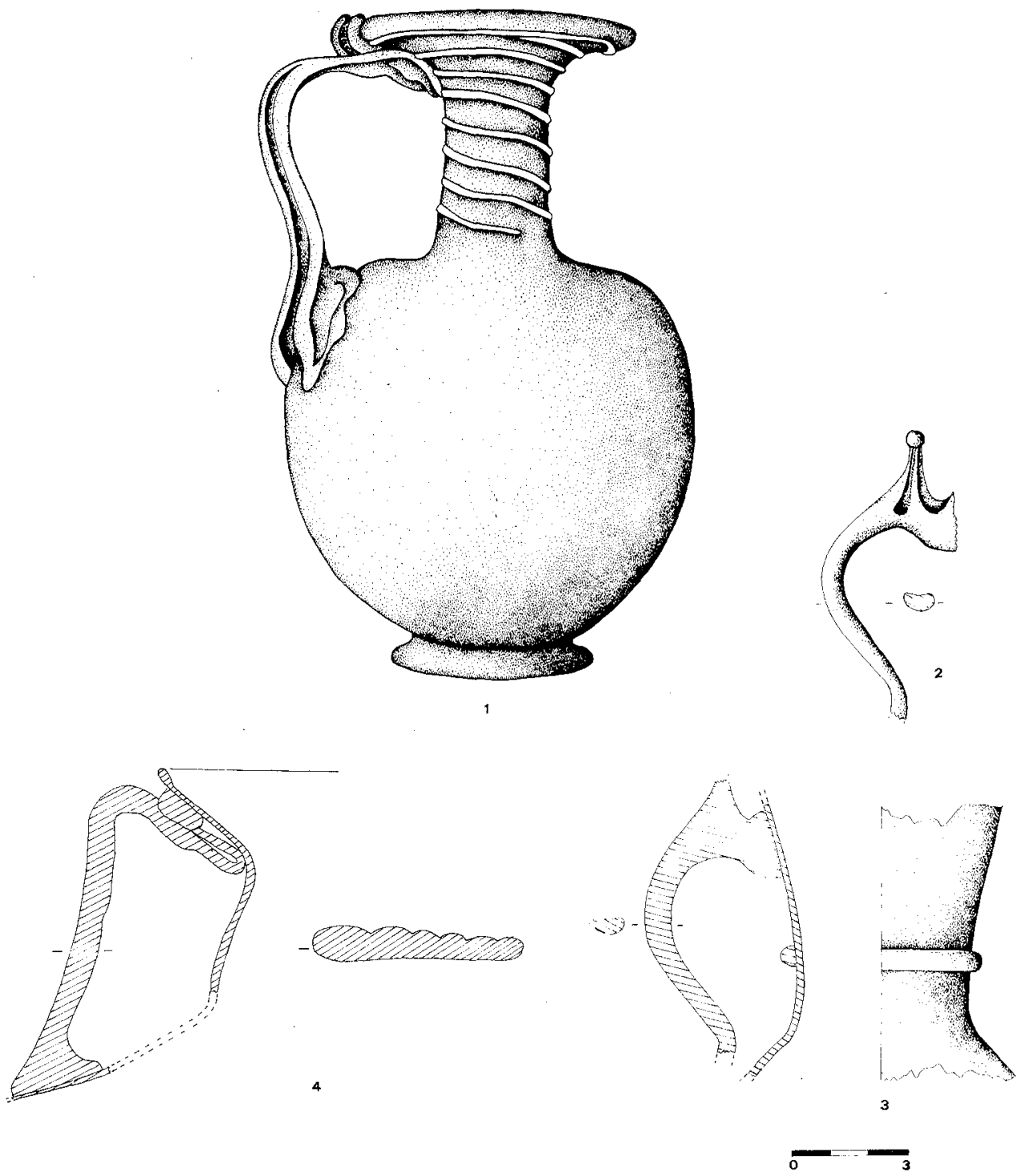

Figura 12.-Jarros: 1-4, jarros diversos.

En nuestra provincia los jarros hallados han sido muy escasos. Pero hay que destacar uno procedente de la Necrópolis del Montañar, Jávea (Fig. 12, 1); se trata de una pieza con cuerpo esférico y típica boca de embudo, su asa es alta y curvada replegándose sobre el borde. El cuello está decorado con hilos en relieve que lo rodean helicoidalmente. Todas estas características nos llevan a la forma 121 de Isings $(1957, p .150)$, que se data en el siglo IV d.C. La necrópolis tuvo una amplia cronología, habiéndose hallado materiales tardorromanos. 


\section{CONCLUSIONES}

El vidrio en nuestra provincia constituye una gran ayuda para el estudio de las relaciones comerciales. Así, ya desde el siglo IV a.C. nuestra costa estaba encuadrada en el Mediterráneo, como lo prueban las constantes apariciones en poblados y necrópolis de materiales importados. El cambio de Era no va a traer ningún cambio y España entra en las vías comerciales que van desde Egipto y Siria a la Europa noroccidental, pasando por Chipre, Grecia e Italia.

Otro aspecto interesante a resaltar del vidrio recogido es que sigue en general la evolución del romano. Así, en las dos primeras centurias de nuestra Era se trata de un vidrio de lujo, que imita frecuentemente a los recipientes metálicos (los vasos soplados en molde o los aríbalos) y a la cerámica, principalmente a la de paredes finas, a la que llegará a sustituir como servicio de mesa. Por otra parte destaca su marcado carácter oriental, como se demuestra por el gran porcentaje de piezas procedentes de aquella zona (los ungüentarios de candelero, de origen chipriota; los vasos decorados con depresiones; los cuencos soplados en molde, sirios; etc.). Técnicamente se impone el soplado al aire libre para la fabricación de recipientes, aunque sigamos encontrando ejemplares moldeados, que se irán haciendo cada vez más raros; también encontramos piezas sopladas en molde, que no es más que una variedad lujosa del soplado. El color es otra característica interesante, ya que, aunque en la primera mitad del siglo I d.C. hallamos vidrio coloreado, ya sea marrón o verde esmeralda, el vidrio verde-azulado va a imponerse hasta ser el predominante.

A partir del siglo III d.C. el cambio es patente en la evolución del vidrio, que ahora se nos presenta con un marcado carácter occidental (vaso troncocónico, las copas de pie alto o los cuencos elipsoides). Al mismo tiempo, aparecen nuevas y rebuscadas formas que se caracterizarán por sus decoraciones: los cabujones, los hilos fundidos o en relieve bajo el borde, las decoraciones pinzadas y el tallado, cuyo resultado más destacado fue la diatreta. Técnicamente, se trata principalmente de vidrio soplado, que ahora presenta una calidad más baja. Su interior suele aparecer lleno de burbujas y estrías, mientras que la superficie está normalmente recubierta por una pátina negra. Su color suele ser incoloro o de tono verde-amarillento, derivando hacia el melado.

En la provincia han sido varios los yacimientos que han proporcionado material tardorromano de estas características. En Elda destacamos el Monastil y las Agualejas; en Elche, el Portus illicitanus. Pero entre todos destaca Lucentum, yacimiento que permanece bajo un barrio de nuestra ciudad y cuyo material procede del vertedero, por lo que carece de cualquier estratigrafía. El vidrio aquí hallado es de gran homogeneidad, habiéndose hallado numerosas piezas del mismo tipo en cuanto a calidad y cronología. Este hecho junto al hallazgo de numerosos residuos vítreos localizados revueltos con el vidrio, nos hacen pensar en la existencia en esa ciudad de fábricas. Esta hipótesis no es nueva, pues ya en el siglo pasado Rico (1893, p. 69) sostenía la existencia de fábricas de vidrio y cerámica en Lucentum, pero la investigación posterior no consideró tales investigaciones, quizá por falta de pruebas, pues el yacimiento está muy arrasado, dadas las continuas obras que en él se efectúan constantemente.

Otro punto interesante es la constante aparición del vidrio en el mundo funerario. En la provincia hemos localizado diversas necrópolis que se sitúan en un período oscuro, que abarcaría entre los siglos V al VII d.C. Se trata de necrópolis hispanorromanas que se caracterizan por la pobreza de su ajuar, entre el que es fácil hallar elementos de adorno o recipientes vítreos, como en Les Jovades (Cocentaina) o Mas Blanc (Penáguila). 


\section{BIBLIOGRAFIA}

ALARÇAO, J. 1976: «Ceramiques diverses et verres», Fouilles de Conimbriga VI, París.

ALMAGRO BASCH, M. 1953-4: «Excavación en la necrópolis romana de Pollentia (Alcudia, Mallorca), Ampurias XV-XVI, Barcelona, pp. 246-247.

- 1955: Las necrópolis de Ampurias I-II, Barcelona.

CABALlERO, L. 1970: «Alconétar. En la vía romana de la Plata. Garrovillas (Cáceres)», E.A.E., 70, Madrid.

- 1974: «La necrópolis tardorromana de Fuentespreadas (Zamora)», E.A.E., 80, Madrid.

CALVI, M. C. 1968: I vetri romani del Museo di Aquileia, Aquilea.

CARRERAS, T. 1982: «El vidre antic», Bulletí informatiu de Prehistoria-Arqueologia de la Diputació de Barcelona, 38, vol. VII.

CORZO SANCHEZ, 1981: «La basílica visigoda de Alcalá de los Gazules», Estudios de Historia y Arqueología medievales, I, Cádiz, pp. 77-90.

CHARLESWORTH, D. 1966: «Roman Square Bottles», Journal of Glass Studies, VIII, pp. 26-40.

GRANADOS, J. 1977: «Estudios de cerámica romana barcelonesa: un vaso de cerámica corintia hallado en la necrópolis romana de las Cortes», Boletín del Seminario de Arte y Arqueología, XLIII, Valladolid, pp. 395-409.

HARDEN, D. 1936: Roman Glass from Karanis, Michigan.

HAYES, J. 1975: Roman and preroman Glass in the Royal Ontario Museum, 1975.

ISINGS, C. 1957: Roman Glass from dated Finds, Groningen.

MEZQUIRIZ DE CATALÀN, M. A. 1978: Pompaelo, I-II, Pamplona.

RAMOS FERNANDEZ, R. 1974: De Hélike a Illici, Alicante.

REMESAL RODRIGUEZ, J. 1979: «La necrópolis sureste de Baelo», E. $A$. E., 104, Madrid.

RICO GARCIA, M. 1893: «Fábricas de vidrio y cerámica en Alicante», El Archivo, VII, pp. 69-78.

SIRET, L. 1906: Villaricos y Herrerías, Madrid.

VESSBERG, D. 1952: «Roman Glass in Cyprus», Opuscula Archaeologica, VII, Stockholm.

VIGIL PASCUAL, M. 1969: El vidrio en el mundo antiguo, Madrid. 